\title{
Effectiveness of the Rigo Chêneau versus Boston-style orthoses for adolescent idiopathic scoliosis: a retrospective study
}

Miriam K. Minsk' ${ }^{1}$, Kristen D. Venuti ${ }^{1}$, Gail L. Daumit ${ }^{2,3,4,5}$ and Paul D. Sponseller ${ }^{1,6^{*}}$

\begin{abstract}
Background: Bracing can effectively treat adolescent idiopathic scoliosis (AIS), but patient outcomes have not been compared by brace type. We compared outcomes of AlS patients treated with Rigo Chêneau orthoses (RCOs) or custom-molded Boston-style thoracolumbosacral orthoses (TLSOs).

Methods: We retrospectively reviewed patient records from one scoliosis center from 1999 through 2014. Patients were studied from initial treatment until skeletal maturity or surgery. Inclusion criteria were a diagnosis of AIS, initial major curve between $25^{\circ}$ and $40^{\circ}$, use of an RCO or TLSO, and no previous scoliosis treatment.

Results: The study included 108 patients (93 girls) with a mean ( \pm standard deviation) age at brace initiation of $12.5 \pm 1.3$ years. Thirteen patients wore an RCO, and 95 wore a TLSO. Mean pre-bracing major curves were $32.7^{\circ} \pm 4.8^{\circ}$ in the RCO group and $31.4^{\circ} \pm 4.4^{\circ}$ in the TLSO group $(p=0.387)$. Mean brace wear time was similar between groups. Mean differences in major curve from baseline to follow-up were $-0.4^{\circ} \pm 9.9^{\circ}$ in the RCO group and $6.9^{\circ} \pm 12.1^{\circ}$ in the TLSO group ( $p=0.028$ ). Percent changes in major curve from baseline to follow-up were $0.0 \% \pm 30.5 \%$ for the RCO group and $21.3 \% \pm 38.8 \%$ for the TLSO group ( $p=0.030$ ). No RCO patients and 34\% of TLSO patients progressed to spinal surgery $(p=0.019)$. At follow-up, major curves improved by $6^{\circ}$ or more in $31 \%$ of the RCO group and $13 \%$ of the TLSO group $(p=0.100)$.

Conclusions: Patients treated with RCOs compared with Boston-style TLSOs had similar baseline characteristics and brace wear time yet significantly lower rates of spinal surgery. Patients with RCOs also had lower mean and percent major curve progression versus those with TLSOs.
\end{abstract}

Keywords: Adolescent, Bracing, Major curve, Orthosis, Outcomes, Scoliosis

\section{Background}

Adolescent idiopathic scoliosis (AIS) affects 2 to $3 \%$ of adolescents between the ages of 10 and 18 years [1,2]. Brace treatment is commonly offered when the spinal curve has reached $25^{\circ}$ [3]. Since the Bracing in Adolescent Idiopathic Scoliosis Trial study in 2013 [4], bracing has been increasingly recognized as an effective nonsurgical means of scoliosis treatment. However, the comparative effectiveness of most types of braces for AIS has not been definitively established [5].

\footnotetext{
* Correspondence: psponse@jhmi.edu

${ }^{1}$ Department of Orthopaedic Surgery, The Johns Hopkins University, Baltimore, MD, USA

${ }^{6}$ Bloomberg Children's Center, 1800 Orleans Street, 7359A, Baltimore, MD 21287, USA

Full list of author information is available at the end of the article
}

A rigid thoracolumbosacral orthosis (TLSO) is a brace worn to minimize progression of AIS. There are various TLSO designs (e.g., Boston, Milwaukee, Wilmington) [6]. Rigo Chêneau orthoses (RCOs) were developed approximately two decades ago, with the intent to combine biomechanical forces in three dimensions, including curve derotation. They use an open pelvis design with anterior opening. However, studies of the RCO are limited, and we know little about its effectiveness, particularly in relation to other braces $[5,7,8]$.

In the current study, we reviewed records of patients treated at one large academic medical center's pediatric orthopedic scoliosis practice who were prescribed full-time bracing for AIS. Our objective was to determine if brace type, specifically the RCO compared with a 
Boston-style TLSO, affected outcomes. Our hypothesis was that different brace designs would lead to different patient outcomes.

\section{Methods}

\section{Study population}

We retrospectively reviewed medical records of patients treated at an academic scoliosis center from 1999 through 2014. The study population consisted of adolescents aged 10 years or older at presentation who met the following criteria: (1) diagnosis of AIS; (2) Risser stage between 0 and 2; (3) major curve between $25^{\circ}$ and $40^{\circ}$; (3) no previous treatment for scoliosis; (4) if female, premenarchal or less than 1 year postmenarchal; (5) prescribed full-time brace treatment; and (6) follow-up until skeletal maturity or surgery.

\section{Measurements}

Outcome variables followed the recommendations of the Scoliosis Research Society (SRS) Committee on Bracing and Nonoperative Management and the Society on Scoliosis Orthopaedic and Rehabilitation Treatment (SOSORT) and incorporated other relevant clinical outcomes $[9,10]$. Outcomes included the following: major curve exceeding $30^{\circ}$ and major curve exceeding $50^{\circ}$, difference in major curve from baseline to follow-up, percent change in major curve, progression to spinal surgery, progression of curve to $45^{\circ}$ or more after bracing, progression to spinal surgery or curve of at least $45^{\circ}$ after bracing, major curve progression of $6^{\circ}$ or more, major curve improvement of $6^{\circ}$ or more, and major curve unchanged (within $5^{\circ}$ ). For the outcomes that included progression to curvature of $45^{\circ}$ or more, we measured the patients whose major curve progressed to at least $45^{\circ}$.

Our primary independent variable was the type of brace. We compared an RCO with a custom Bostonstyle TLSO. Patients self-selected their orthotists and brace type. Follow-up orthopedist recommendations were the same for all patients: in-brace radiography and clinic visit 4 weeks after treatment initiation, then outof-brace radiography and clinic visits every 4 months before menarche and every 6 months after menarche. We abstracted information on age, sex, race, curve location, pre-bracing initial major curve magnitude, prebracing Risser stage, initial in-brace major curve, time in brace, and mean patient-reported number of hours the brace was worn in Risser stages 0 and 1 and overall. We recorded information for the total course of treatment for each patient and calculated the mean brace wear time for the course of treatment.

We performed univariate and bivariate descriptive analyses, including Student $t$ tests, Fisher exact tests, and $x^{2}$ tests, comparing baseline characteristics and outcomes. A two-sided alpha with $p<0.05$ was considered statistically significant.

\section{Results}

Baseline characteristics

Of the 108 patients (93 girls) who met the inclusion criteria, the mean age at treatment initiation was $12.5 \pm 1.3$ years (Table 1). Ninety-five patients were treated with a TLSO, and 13 patients were treated with an RCO. Of the study population, $72 \%$ were Caucasian and $15 \%$ were African American. Major curves were mainly thoracic (47\%), lumbar (22\%), or thoracic and thoracolumbar (18\%). The mean pre-brace major curves were $31.6^{\circ} \pm 4.4^{\circ}$ overall, $32.7^{\circ} \pm 4.8^{\circ}$ in the RCO group, and $31.4^{\circ} \pm 4.4^{\circ}$ in the TLSO group, corresponding to $52 \%$ of patients having an initial pre-brace major curve of more than $30^{\circ}$. Sixty-three percent of patients began bracing at Risser stage $0,22 \%$ at Risser stage 1, and 15\% at Risser stage 2. Demographic and clinical characteristics at baseline were similar for patients in both groups.

\section{Treatment and outcomes}

We followed all patients until skeletal maturity or progression to surgery, whichever came first. Mean initial in-brace major curves were $22.6^{\circ} \pm 6.4^{\circ}$ in the $\mathrm{RCO}$ group and $22.6^{\circ} \pm 7.2^{\circ}$ in the TLSO group $(p=0.924)$ (Table 2). In-brace correction of major curve from baseline of at least $35 \%$ was achieved in $42 \%$ of the RCO group and $36 \%$ of the TLSO group ( $p=0.943$, data not shown). Patients in the RCO group wore the brace for a mean $17.0 \pm 6.1 \mathrm{~h}$ per day, and patients in the TLSO group wore the brace for a mean $16.1 \pm 5.2 \mathrm{~h}$ per day $(p=0.641)$.

After bracing was complete, the mean final measurements for major curves were $32.3^{\circ} \pm 10.4^{\circ}$ (RCO group) and $38.3^{\circ} \pm 13.5^{\circ}$ (TLSO group) $(p=0.077)$ (Table 2). Forty-six percent of RCO patients had a major curve at follow-up of greater than $30^{\circ}$, compared with $67 \%$ of TLSO patients $(p=0.133)$. The mean difference in major curves from baseline to follow-up was $-0.4^{\circ} \pm 9.9^{\circ}$ for the RCO group versus $6.9^{\circ} \pm 12.1^{\circ}$ for the TLSO group $(p=0.028)$. Figure 1 shows each patient's change in major curve magnitude from baseline to follow-up. The percent changes in major curves from baseline to follow-up were $0.0 \% \pm 30.5 \%$ for the RCO group and $21.3 \% \pm 38.8 \%$ for the TLSO group $(p=0.030)$ (Table 2 ). No patients in the RCO group progressed to surgery, compared with 32 patients in the TLSO group $(p=0.019)$. Fifteen percent of patients in the RCO group had a final major curve of $45^{\circ}$ or greater or progressed to spinal surgery, compared with $38 \%$ of patients in the TLSO group ( $p=0.133)$. At follow-up, major curves improved by $6^{\circ}$ or more in $31 \%$ of the RCO group and $13 \%$ of the TLSO group $(p=0.100)$. 
Table 1 Demographic and clinical characteristics at baseline for 108 patients with adolescent idiopathic scoliosis

\begin{tabular}{|c|c|c|c|c|c|c|c|}
\hline \multirow[t]{3}{*}{ Characteristics } & \multicolumn{7}{|l|}{ Patients } \\
\hline & \multicolumn{2}{|c|}{ All $(n=108)$} & \multicolumn{2}{|c|}{ RCO group $(n=13)$} & \multicolumn{2}{|c|}{ Boston-style TLSO group $(n=95)$} & \multirow[t]{2}{*}{$P$} \\
\hline & Mean (SD) & $n(\%)$ & Mean (SD) & $n(\%)$ & Mean (SD) & $n(\%)$ & \\
\hline Age (years) & $12.5(1.3)$ & & $12.5(1.3)$ & & $12.5(1.3)$ & & 0.762 \\
\hline Female sex & & $93(86)$ & & $11(85)$ & & $82(86)$ & 1.00 \\
\hline Race & & & & & & & 0.282 \\
\hline Caucasian & & $78(72)$ & & $10(77)$ & & $68(72)$ & \\
\hline African American & & $16(15)$ & & $0(0)$ & & $16(17)$ & \\
\hline Hispanic & & $1(1)$ & & $0(0)$ & & $1(1)$ & \\
\hline Asian/Pacific Islander & & $2(2)$ & & $0(0)$ & & $2(2)$ & \\
\hline Other & & $11(10)$ & & $3(23)$ & & $8(8)$ & \\
\hline \multicolumn{8}{|l|}{ Major curve location } \\
\hline Thoracic & & $51(47)$ & & $5(38)$ & & $46(48)$ & 0.500 \\
\hline Thoracolumbar & & $3(3)$ & & $0(0)$ & & $3(3)$ & 1.00 \\
\hline Lumbar & & $24(22)$ & & $1(7.7)$ & & $23(24)$ & 0.290 \\
\hline Double major & & $0(0)$ & & $0(0)$ & & $0(0)$ & \\
\hline Double thoracic & & $9(8)$ & & $3(23)$ & & $6(6)$ & 0.075 \\
\hline Thoracic and thoracolumbar & & $19(18)$ & & $4(31)$ & & $15(16)$ & 0.238 \\
\hline Triple & & $2(2)$ & & $0(0)$ & & $2(2)$ & 1.00 \\
\hline Major curve $\left(^{\circ}\right)$ & $31.6(4.4)$ & & $32.7(4.8)$ & & $31.4(4.4)$ & & 0.387 \\
\hline Major curve $>30^{\circ}$ & & $56(52)$ & & $7(54)$ & & $49(51)$ & 0.878 \\
\hline Risser stage & & & & & & & 0.710 \\
\hline 0 & & $68(63)$ & & $7(54)$ & & $61(64)$ & \\
\hline 1 & & $24(22)$ & & $4(31)$ & & $20(21)$ & \\
\hline 2 & & $16(15)$ & & $2(15)$ & & $14(15)$ & \\
\hline
\end{tabular}

RCO Rigo Chêneau orthosis, TLSO thoracolumbosacral orthosis, SD standard deviation

\section{Discussion}

In this retrospective review of a large academic medical center's patients with AIS and their experience with fulltime brace treatment, we found that patients treated with RCOs were substantially less likely to progress to spinal surgery and had smaller mean change and smaller percent increase in major curves from treatment initiation through follow-up than patients treated with a TLSO, despite similar baseline characteristics and brace wear time. The outcomes of curve progression less than $45^{\circ}$ or progression to surgery and major curve improvement of at least $6^{\circ}$ were not statistically different; however, they appeared to favor RCOs. Although previous studies have shown the benefits of bracing $[4,11-13]$ and the benefits of the RCO for treatment of AIS $[7,8]$, none has compared efficacy of the RCO with other orthoses. For this study, we incorporated guidelines from the SRS Bracing Committee and SOSORT to establish our inclusion criteria [10] and tracked patients from early Risser stages until maturity or surgery to understand the effects of brace type, specifically RCO versus TLSO, on outcomes.
We consider our outcomes for brace treatment in relation to previous studies' findings. In the Bracing in Adolescent Idiopathic Scoliosis Trial study, 72\% of those with TLSO bracing had curve progression to less than $50^{\circ}$ [4]. Similarly, our study showed that $68 \%$ of patients with TLSO bracing had major curve progression to less than $45^{\circ}$ [4]. Previous studies, mostly using Milwaukee TLSO braces, have shown a large spectrum of success rates for a range of curve outcomes, likely because of dissimilarity in brace quality, patient characteristics, and decision thresholds for spinal surgery [14-18]. Most of these studies took place before SRS and SOSORT guidelines on reporting; thus, standards of outcome measurement and participant selection varied [10].

Little research has been published on outcomes for RCOs. Zaborowska-Sapeta et al. [8] reported on 79 patients with RCOs in Poland. In their study, $12.9 \%$ of patients progressed to a major curve greater than $50^{\circ}$ at final follow-up, with a mean major curve increase of $9.2^{\circ}$ for the overall study population [8]. Although we used the SRS-recommended outcome of $45^{\circ}$, our results are comparable to those of Zaborowska-Sapeta et al. [8]. 
Table 2 Bracing treatment and outcomes for 108 patients with adolescent idiopathic scoliosis

\begin{tabular}{|c|c|c|c|c|c|c|c|}
\hline \multirow[t]{3}{*}{ Parameter } & \multicolumn{6}{|l|}{ Patients } & \multirow[t]{3}{*}{$P$} \\
\hline & \multicolumn{2}{|l|}{ All $(n=108)$} & \multicolumn{2}{|c|}{ RCO group $(n=13)$} & \multicolumn{2}{|c|}{ Boston-style TLSO group $(n=95)$} & \\
\hline & Mean (SD) & $n(\%)$ & Mean (SD) & $n(\%)$ & Mean (SD) & $n(\%)$ & \\
\hline Initial in-brace major curve ${ }^{\mathrm{a}}\left(^{\circ}\right)$ & $22.8(7.2)$ & & $22.6(6.4)$ & & $22.6(7.2)$ & & 0.924 \\
\hline Percent initial in-brace major curve correction ${ }^{a}$ & $28.4(20.1)$ & & $31.5(15.2)$ & & $27.8(20.1)$ & & 0.538 \\
\hline Time in brace (year) & $2.4(1.4)$ & & $2.8(0.9)$ & & $2.4(1.4)$ & & 0.193 \\
\hline \multicolumn{8}{|l|}{ Brace wear time per day (h) } \\
\hline All patients ${ }^{\mathrm{b}}$ & $16.2(5.3)$ & & $17.0(6.1)$ & & $16.1(5.2)$ & & 0.641 \\
\hline Patients with Risser stage 0 or $1^{c}$ & $17.0(5.8)$ & & $18.9(5.8)$ & & $16.8(5.8)$ & & 0.296 \\
\hline Final major curve $\left(^{\circ}\right)$ & $37.6(13.3)$ & & $32.3(10.4)$ & & $38.3(13.5)$ & & 0.077 \\
\hline \multicolumn{8}{|l|}{ Final major curve } \\
\hline$>30^{\circ}$ & & $70(65)$ & & $6(46)$ & & $64(67)$ & 0.133 \\
\hline$>50^{\circ}$ & & $18(17)$ & & $1(8)$ & & $17(18)$ & 0.464 \\
\hline Change in major curve from baseline ${ }^{d}\left(^{\circ}\right)$ & $6.0(12.1)$ & & $-0.4(9.9)$ & & $6.9(12.1)$ & & 0.028 \\
\hline Percent change in major curve from baseline & $18.6(38.9)$ & & $0.0(30.5)$ & & $21.3(38.8)$ & & 0.030 \\
\hline Progression to surgery & & $32(30)$ & & $0(0)$ & & $32(34)$ & 0.019 \\
\hline \multicolumn{8}{|l|}{ At skeletal maturity } \\
\hline Major curve $\geq 45^{\circ}$ & & $32(30)$ & & $2(15)$ & & $30(32)$ & 0.337 \\
\hline Progression to surgery or major curve $\geq 45^{\circ}$ & & $38(35)$ & & $2(15)$ & & $36(38)$ & 0.133 \\
\hline \multicolumn{8}{|l|}{ Major curve change } \\
\hline Progression $\geq 6^{\circ}$ & & $52(48)$ & & $5(38)$ & & $47(49)$ & 0.556 \\
\hline Decrease $\geq 6^{\circ}$ & & $16(15)$ & & $4(31)$ & & $12(13)$ & 0.100 \\
\hline Unchanged $\left( \pm 5^{\circ}\right)$ & & $40(37)$ & & $4(31)$ & & $36(38)$ & 0.764 \\
\hline
\end{tabular}

$S D$ standard deviation, $R C O$ Rigo Chêneau orthosis, TLSO thoracolumbosacral orthosis

${ }^{\mathrm{a}} n=83$ (RCO, $n=12 ;$ TLSO, $\left.n=70\right)$

${ }^{\mathrm{b}} n=107$ (RCO, $n=13$; TLSO, $\left.n=94\right)$

${ }^{\mathrm{C}} \mathrm{RCO}, n=10$; TLSO, $n=71$

${ }^{d} n=95(\mathrm{RCO}, n=11 ; \mathrm{TLSO}, n=84)$

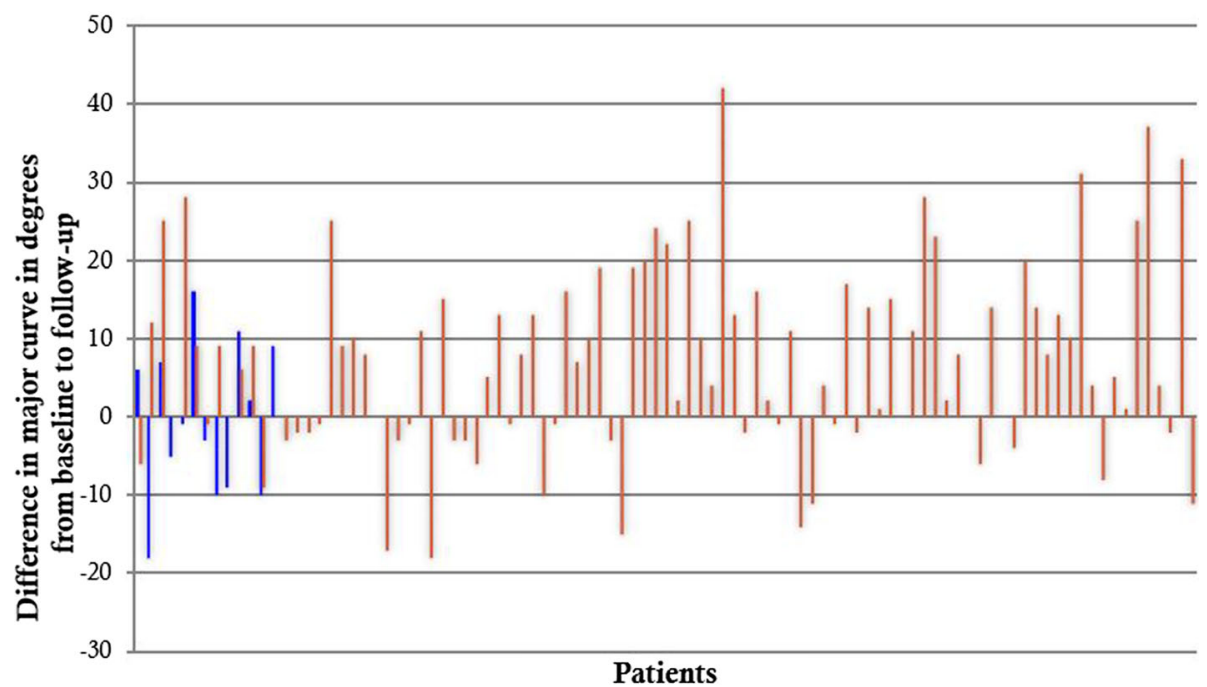

Fig. 1 Difference in major curve after treatment with Rigo Chêneau orthoses (blue lines) compared with Boston-style thoracolumbosacral orthoses (red lines) in 108 patients with adolescent idiopathic scoliosis 
However, our population had a lower mean change in major curve from baseline to follow-up with the RCO. Ovadia et al. [7] published the results of 93 patients in Israel treated with RCOs and found that $84 \%$ of patients' curves progressed by less than $5^{\circ}$. Although we studied a smaller number of patients with RCOs than these two international reports, our study is an important addition to the research because it is one of the first to compare outcomes after RCO use versus general Boston-style TLSO bracing.

Several factors could have contributed to the favorable outcomes for RCOs compared with TLSOs in our study. First, the RCO construction with three-dimensional corrective forces may have a better effect on scoliosis curves compared with the TLSO. Second, the lighter weight of the RCO and more open design may have made it more desirable and comfortable for patients to wear, leading to increased compliance. However, we did not observe a difference in patient-reported mean wear time between brace types during the course of follow-up. Third, because this was an observational study of clinical practice, families had a choice of orthotists and orthoses. Although we did not measure how families made these decisions, we believe variation in geographical distance to orthotists and heterogeneity of insurance coverage for orthoses could have influenced the type of brace adolescents received. In addition, families who chose the RCOs could have had other factors that made their adolescents more likely to have successful bracing outcomes.

This study has limitations. Despite the large number of records encompassing 15 years of a busy, academic scoliosis clinical practice, we had a relatively small sample of patients using RCOs compared with the two international reports, and this may have limited our ability to detect statistically significant differences in some measures $[7,8]$. RCO braces were principally made by one skilled orthotist in the region, which contributed to their lower frequency. Despite this, the relative comparability of our outcomes with previous TLSO and $\mathrm{RCO}$ studies provides face validity. In addition, this was a retrospective review of an outpatient clinical practice, and we did not have quality-of-life measures, objective monitoring of time wearing the brace, or blinded, independent outcome assessment. Although self-reports tend to overestimate brace wear time [19], it is unlikely that reported wear time would differ systematically between patients with TLSOs and RCOs in this review of a real-world clinical practice.

Another potential limitation was that although the percent initial in-brace major curve correction appeared to be better in RCOs compared with TLSOs, the difference was not statistically significant, as we may have expected given the positive RCO outcomes at the end of treatment. This could have been caused in part by the smaller number of RCOs and by the fact that if the initial correction was not clinically acceptable to the orthopedist, he would recommend the patient return for brace adjustments to achieve optimal correction. Further, in-brace radiography was generally not performed. Thus, the 1-month in-brace measurements presented here may underestimate actual in-brace correction, particularly for RCOs. In addition, the in-brace measured curve correction reflects coronal changes only, not rotational changes, which could not be studied. However, on clinical assessment such as out-of-brace examination of forward bending, the orthopedist noticed that rotational prominence often diminished in RCO-treated patients. The RCO's influence on curve derotation may be particularly important for its effectiveness in treating scoliosis; however, future research is needed to elucidate how this mechanism contributes to bracing success [7].

There are several strengths of our report. We followed guidelines for patient inclusion and choice of clinical outcome variables $[9,10]$. Our results provide a realworld comparison of patient experience with brace types in a large outpatient scoliosis practice. This use of SRS and SOSORT criteria to compare outcomes by brace type is rare in prior studies. Moreover, the similar clinical characteristics at baseline allow an assessment of differences between brace types, despite a relatively small sample size for the RCO group.

\section{Conclusions}

In this large retrospective review of an academic outpatient scoliosis practice, patients treated with RCOs were substantially less likely to progress to spinal surgery than those treated with Boston-style TLSOs. Patients treated with RCOs also had smaller mean change and smaller percent increase in major curves from treatment initiation through follow-up. Future studies should examine differences in outcomes by brace type in other settings and in larger samples, and they should investigate the impact of the rotational dimension of correction with RCOs. Clinicians may consider increasing use of RCOs for AIS.

\begin{abstract}
Abbreviations
AIS: Adolescent idiopathic scoliosis; RCO: Rigo Chêneau orthosis; SOSORT: Society on Scoliosis Orthopaedic and Rehabilitation Treatment; SRS: Scoliosis Research Society; TLSO: Thoracolumbosacral orthosis
\end{abstract}

\section{Acknowledgements}

Not applicable.

Funding

Not applicable. There was no funding for this study.

Availability of data and materials

The data that support the findings of this study could be available on request from the corresponding author after additional human subject research approval is obtained. The data are not publicly available because of information that could compromise research participant privacy. 


\section{Authors' contributions}

MKM designed the data abstraction, abstracted the data from the records, performed the analyses, and drafted the manuscript. KDV was a major contributor in the data abstraction design and participated in writing the manuscript. GLD contributed to the analyses, interpretation of the data, and editing the manuscript. PDS designed the study and was a major contributor to the interpretation of the data and editing the manuscript. All authors provided approval of the final manuscript.

\section{Competing interests}

The authors declare that they have no competing interests.

\section{Consent for publication}

Not applicable.

\section{Ethics approval and consent to participate}

The Office of Human Subjects Research institutional review boards at The Johns Hopkins University School of Medicine approved this retrospective study and waived informed consent (protocol 00070565).

\section{Publisher's Note}

Springer Nature remains neutral with regard to jurisdictional claims in published maps and institutional affiliations.

\section{Author details}

'Department of Orthopaedic Surgery, The Johns Hopkins University, Baltimore, MD, USA. ${ }^{2}$ Division of General Internal Medicine, The Johns Hopkins University School of Medicine, Baltimore, MD, USA. ${ }^{3}$ Welch Center for Prevention, Epidemiology, and Clinical Research, The Johns Hopkins University, Baltimore, MD, USA. ${ }^{4}$ Department of Epidemiology, The Johns Hopkins Bloomberg School of Public Health, Baltimore, MD, USA ${ }^{5}$ Department of Health Policy and Management, The Johns Hopkins Bloomberg School of Public Health, Baltimore, MD, USA. ${ }^{6}$ Bloomberg Children's Center, 1800 Orleans Street, 7359A, Baltimore, MD 21287, USA.

Received: 24 October 2016 Accepted: 28 February 2017

Published online: 20 March 2017

\section{References}

1. Nachemson A, Lonstein J, Weinstein S. Report of the SRS Prevalence and Natural History Committee 1982. Presented at the Scoliosis Research Society 17th Annual Meeting, Denver, CO, September 22-25, 1982.

2. Weinstein SL, Dolan LA, Cheng JCY, Danielsson A, Morcuende JA. Adolescent idiopathic scoliosis. Lancet. 2008:371(9623):1527-37.

3. Parent S, Newton PO, Wenger DR. Adolescent idiopathic scoliosis: etiology, anatomy, natural history, and bracing. Instr Course Lect. 2005:54:529-36.

4. Weinstein SL, Dolan LA, Wright JG, Dobbs MB. Effects of bracing in adolescents with idiopathic scoliosis. N Engl J Med. 2013:369(16):1512-21.

5. Negrini S, Aulisa AG, Aulisa L, Circo AB, de Mauroy JC, Durmala J, Grivas TB, Knott P, Kotwicki T, Maruyama T, Minozzi S, O'Brien JP, Papadopoulos D, Rigo M, Rivard CH, Romano M, Wynne JH, Villagrasa M, Weiss HR, Zaina F. 2011 SOSORT guidelines: orthopaedic and rehabilitation treatment of idiopathic scoliosis during growth. Scoliosis. 2012;7(1):3.

6. Zaina F, De Mauroy JC, Grivas T, Hresko MT, Kotwizki T, Maruyama T, Price N, Rigo M, Stikeleather L, Wynne J, Negrini S. Bracing for scoliosis in 2014: state of the art. Eur J Phys Rehabil Med. 2014;50(1):93-110.

7. Ovadia D, Eylon S, Mashiah A, Wientroub S, Lebel ED. Factors associated with the success of the Rigo System Chêneau brace in treating mild to moderate adolescent idiopathic scoliosis. J Child Orthop. 2012;6(4):327-31.

8. Zaborowska-Sapeta K, Kowalski IM, Kotwicki T, Protasiewicz-Faldowska H, Kiebzak W. Effectiveness of Chêneau brace treatment for idiopathic scoliosis: prospective study in 79 patients followed to skeletal maturity. Scoliosis. 2011;6(1):2.

9. Negrini S, Hresko TM, O'Brien JP, Price N, Boards S, Committee SRSN-O. Recommendations for research studies on treatment of idiopathic scoliosis: consensus 2014 between SOSORT and SRS non-operative management committee. Scoliosis. 2015;10:8

10. Richards BS, Bernstein RM, D'Amato CR, Thompson GH. Standardization of criteria for adolescent idiopathic scoliosis brace studies. SRS Committee on Bracing and Nonoperative Management. Spine (Phila Pa 1976). 2005;30(18):2068-75
11. Katz DE, Herring JA, Browne RH, Kelly DM, Birch JG. Brace wear control of curve progression in adolescent idiopathic scoliosis. J Bone Joint Surg Am. 2010;92(6):1343-52.

12. Nachemson AL, Peterson LE, members of The Brace Study Group of the Scoliosis Research Society. Effectiveness of treatment with a brace in girls who have adolescent idiopathic scoliosis. A prospective, controlled study based on data from the Brace Study of the Scoliosis Research Society. J Bone Joint Surg Am. 1995;77(6):815-822.

13. Rowe DE, Bernstein SM, Riddick MF, Adler F, Emans JB, Gardner-Bonneau D. A meta-analysis of the efficacy of non-operative treatments for idiopathic scoliosis. J Bone Joint Surg Am. 1997;79(5):664-74.

14. Danielsson AJ, Hasserius R, Ohlin A, Nachemson AL. A prospective study of brace treatment versus observation alone in adolescent idiopathic scoliosis. A follow-up mean of 16 years after maturity. Spine (Phila Pa 1976). 2007:32(20):2198-207.

15. Fernandez-Feliberti R, Flynn J, Ramirez N, Trautmann M, Alegria M. Effectiveness of TLSO bracing in the conservative treatment of idiopathic scoliosis. J Pediatr Orthop. 1995;15(2):176-81.

16. Goldberg CJ, Moore DP, Fogarty EE, Dowling FE. Adolescent idiopathic scoliosis: the effect of brace treatment on the incidence of surgery. Spine (Phila Pa 1976). 2001;26(1):42-7.

17. Lonstein JE, Winter RB. The Milwaukee brace for the treatment of adolescent idiopathic scoliosis. A review of one thousand and twenty patients. J Bone Joint Surg Am. 1994;76(8):1207-21.

18. Noonan K, Weinstein SL, Jacobson WC, Dolan LA. Use of the Milwaukee brace for progressive idiopathic scoliosis. J Bone Joint Surg (Br). 1996;78(4):557-67.

19. Morton A, Riddle R, Buchanan R, Katz D, Birch J. Accuracy in the prediction and estimation of adherence to bracewear before and during treatment of adolescent idiopathic scoliosis. J Pediatr Orthop. 2008;28(3):336-41.

\section{Submit your next manuscript to BioMed Central} and we will help you at every step:

- We accept pre-submission inquiries

- Our selector tool helps you to find the most relevant journal

- We provide round the clock customer support

- Convenient online submission

- Thorough peer review

- Inclusion in PubMed and all major indexing services

- Maximum visibility for your research

Submit your manuscript at www.biomedcentral.com/submit
Biomed Central 